attacks of labour-like pains and burning sensations in the lower abdomen. For the last few months there had also been a thin white vaginal discharge. Mioturition had been normal and the bowels had been regular throughout. On palpation of the abdomen nothing abnormal was discovered but vaginal examination revealed the presence of a tumour lying in the pouch of Douglas. 'The tumour was of the size of the closed fist, was hard, not tender, more or less fixed, and lay in close relationship to the nterus. It gave to the examining finger the sensation given by a fibromyoma. Immediately in front of it was the cervix, which was displaced forwards close to the pubic symphysis.

Dr. Fenton opened the abdomen on Jan. 15th and explored the pelvis. A large fibroid uterus was found. The tumour was discovered to be growing chiefly from the posterior wall of the uterus and to be burrowing its way down towards the cervix. The uterus with its contained fibroid was removed by supravaginal hysterectomy. Both uterine appendages were removed along with the uterus. The abdominal wound was sewn up in three layers. Recovery was rapid and uneventful except for a slight rise of temperature on the second, third, and fourth days after operation, the highest point reached being $100 \cdot 4^{\circ} \mathrm{F}$. The patient left the hospital on Feb. 3rd, the twentieth day after operation.

An examination of the specimen removed at operation showed an enlarged uterus with both appendages attached. On incising the uterus its posterior wall contained a single interstitial fibromyoma of the size of a cricket ball which was growing down behind the cervix. It presented the red, livercoloured, loose-textured appearance characteristic of red degeneration. Both uterine appendages appeared to be perfectly normal. Microscopically the sections were found to take on the stain in an irregular and patchy manner, so that portions of the section showed interlacing bundles of fibrous and muscular tissue, in which, as in undegenerated fibromyomata, the nuclei were deeply stained and the muscle bundles clearly differentiated. In adjacent parts the nuclei were unore faintly stained, forming " nuclear ghosts," whilst in other place; there was an almost entire disappearance of the nuclei. In these places the muscle bundles had also failed to take the stain well and appeared granular and transversely fragmented, having also a somewhat hyaline or swollen appearance, so that the outlines of the individual muicle fibres can only be recognised with difficulty.

CASE 2.-The patient, aged 40 years, was admitted into the Chelsea Hospital for Women under the care of Dr. Bonney on Nov. 2nd, 1903, complaining of swelling of the abdomen. she had been married four years and was sterile. The catamenia had always been regular, lasting four days, and had been very profuse, necessitating the use of 18 diapers. There were no clots until the last period and there had never been any pain. The first symptom to be noticed was swelling in the left iliac region. This was two years before. The abdominal enlargement gradually increased until September. 1903 : since then when "she caught a very severe cold" it had become much larger. There had been an absence of pain throughout. There had been no vaginal discharge and micturition and the bowels had been normal. On abdominal examination a large tumour-mass of irregular outline was found to occupy the lower abdomen and to extend slightly above the level of the umbilicus. It was of very dense consistence and slightly moveable. No souffle could be detected over it. On vaginal examination the cervix was almost obliterated from the universal distension which the uterus had undergone from its occupation by the tumour. It was freely moveable.

On Nov. 10th Dr. Bonney performed abdominal hysterectomy, removing the right, but leaving the left, ovary. Recovery was rapid and uneventful, the highest temperature after operation being $99.6^{\circ} \mathrm{F}$., and the patient was discharged from hospital on Nov. 27th, 17 days after operation.

In this case also the tumour was a single interstitial fibroniz rma rather larger than the closed fist. It was well encapsuled and of the typical homogeneous mahogany-red colour, having also the faint fishy odour, due probably to the presence of trimethylamine. Microscopically there were the uneven and patchy staining of the sections, the appearance in places of "nuclear ghosts" and the almost entire disappearance of nuclei in other places, and the muscle bundles displaying the granular and transversely fragmented or swollen hyaline appearance, with difficulty of recognition of the outlines of the unstriped muscular fibres so characteristic of this condition.

\section{ADENOMYOMA OF THE UTERUS.}

By S. J. MURDOCH CAMERON, M.B. GlasG., LA'TE SENIOR BESIDENT' MEDICAL OFFICER, MATYERITYY HOSPITAL, GLASGOW;

AND

ARCHIBALD LEITCH, M.B. GT.ASG., SENIOR HOUSE SURATEN, CANCER HOSPITAL, LONDON.

ADENOMYOMA of the uterus has escaped proper recognition in this country. With the exception of a paper recently published by Cameron and Taylor ${ }^{1}$ we can find no detailed account in British medical literature; since then a few specimens have been shown at the medical societies. We have had the opportunity of investigating several others, some of which are herein referred to, in a comparatively short period of time, a circumstance which leads us to believe that these tumours are not very uncommon and that a routine microscopic examination of uteri, the seat of so-called fibroids, would bring to light many more cases of this interesting condition.

As the name implies, these tumours are new growths composed of muscular and gland elements, the latter typically being imbedded in a richly cellular connective tissue. Situated anteriorly, posteriorly, or laterally in the uterus, subserous, interstitial, or submucous, they have in almost all respects the general macroscopic characteristics of a fibromyoma, with which, indeed, they are sometimes associated, as two of our cases show. 'There are perhaps only two points which may lead to a diagnosis - the absence of a definite capsule and the absence of whorls so characteristic of fibromyomata. Their commonest situation is dorsally near one or other of the tubal angles. They vary in consistence and have been classified as hard, cystic, soft, and telangiectatic.

The clinical characters are those of fibromyomata, from which we do not think they can be distinguished by examination. Severe dysmenorrhoea and excessive hæmorrhage are, as a rule, marked features and considerably affect the patient's general health. Sterility is by no means an invariable accompaniment and not one of the cases we have seen has been pathologically so, though, according to Freund, the majority are barren. They may have a frail childhood, a laggard puberty, an arrestment of the growth of the sexual organs, and they usually suffer from anæmia. When the tumour occurs in its commonest situation Funke proposes the following as a means of clinical diagnosis : (1) localisation of the tumour at one or other of the tubal openings in the uterus; (2) the diffusely infiltrated consistence of the growth; (3) painfulness on palpation; (4) the severity of the symptoms produced by such a small lesion; (5) the absolutely normal condition of the tube itself; and (6) the improbability of a circumscript infiltration of a part of the uterus amidst healthy surroundings being due to inflammatory processes.

We have little doubt that adenomyomata imperil the life of the patient much more than ordinary fibromyomata. Their association with adenocarcinoma has been noted by several observers, ${ }^{2}$ and even in the most regularly formed adenomyomata it is doubtful if one can reckon the possible powers of infiltration. Hysterectomy is therefore the only treatment and when removed successfully the result to the patient is excellent. Castration is useless and in no way influences the tumour growth. ${ }^{3}$

Microscopically they are composed of gland tubules imbedded in muscular tissue. The gland cells may abut directly on the muscular fibres but in the great majority of cases there is more or less intervening cellular tissue. The relative proportion of the constituents determines the consistence of the tumour, hard adenomyoma having a preponderance of muscular tissue, soft adenomyoma being composed mostly of adenomatous and lymphadenoid tissue. The tubules may be much distended and cystic spaces so formed are obvious to the naked eyc-cystic adenomyomata. The tubules are composed of a single layer of columnar, sometimes ciliated' (see Fig. 1), epithelial cells, each of which

1 Journal of Obstetries and Gynæcology, March, 1904. Cullen and others 3 Ibid. 
contains a single rouncl, oval, or even rod-shaped nucleus of good staining property. 'The basement membrane is intact. Where the tubules are dilated the epithelium becomes cubical, flattened, or is quite lost. 'The spaces contain clear fluid, in which maly be found a few red blood corpuscles or the remnants of epithelial cells, nuclei with some attached

FIG. 1.

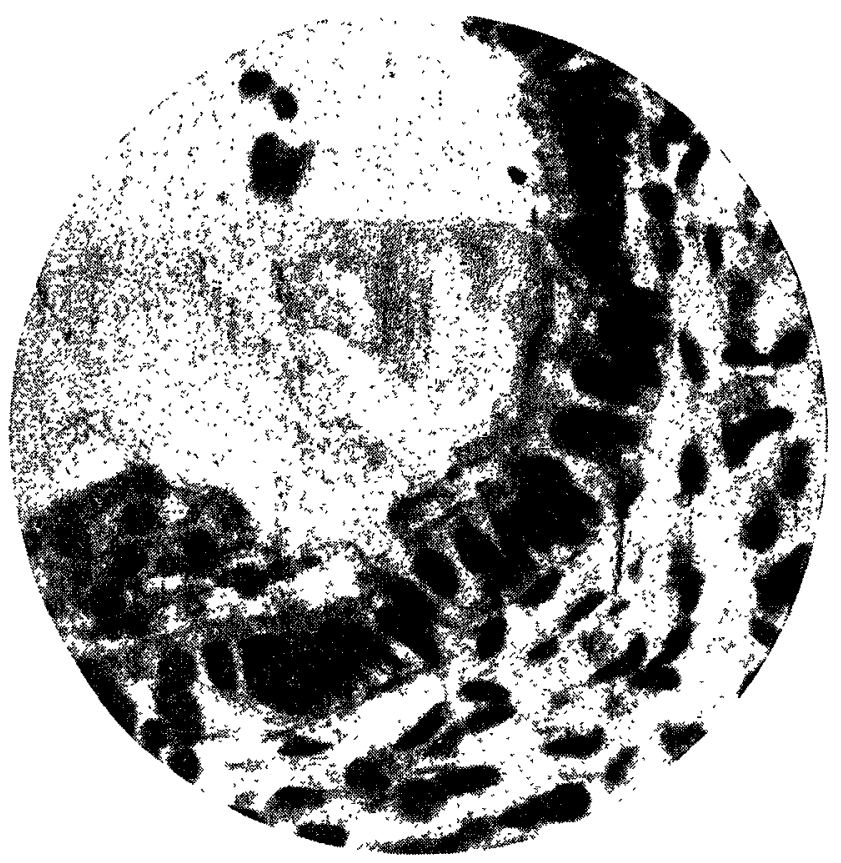

Section showing gland epithelium and surrounding lymphadenoid stroma. Near the centre the cilia are shown. (From Case 4.)

protoplasm. Surrounding the tubules is a richly cellular lymphadenoid stroma composed of round, spindle-shaped, or many branched cells with round nuclei-a tissue identical with the extraglandular stroma of the normal corporeal endometrium. A varying number of tubules are imbedded in, and separated from each other and the surrounding muscle by, this cellolar mass; there is usually a central acinus larger than the others and their relative position, shown in Fig. 2, like foot-tracks on soil, has been described

FIG. 2.

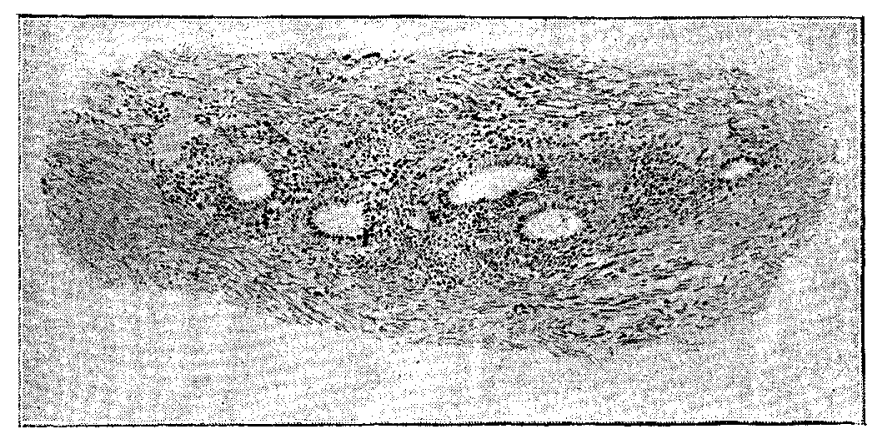

Camera-incida drawing of a glandular islet surrounded by muscle.

as the "goose-step arrangement." ${ }_{1}$ In those tumours in 'which the lymphadenoid tissue is at a minimum this arrangement is lost and the tubules are scattered over the section separated by muscular strands. In the same section one may find bath conditions-the association of several acini in a cellular islet and the rlirect juxtaposition of gland and muscle without intervening stroma. In tumours belonging to the latter type there is a tendency to intraglandular inversion of the epithelium, is fold of epithelium still keeping its basement membrane intact orows into the lumen and is approached by a similar plication from the opposite side the epithelial summits neet and, losing their epithelium, coalesce; and the basement membranes offering no resistance the two processes of ingrowing fibrous tissue become continuous. At other parts in place of complete glandular subdivision such as this thele is a simple intracystic growth, a more or less dichotomons branching of the inverting epithelium. 'The infiltrating character of the growth combined with this tendency seems to us to raise it from the category of typically simple tumours. As in fibromyomata, the relative proportions of muscular and fibrous tissue vary. Well-formed blood-vessels, frequently with hypertrophied coats, are found in the muscular tissue as well as more delicate vessels in the cellular islets; in the very soft telangiectatic variety of adenomyomata the bloodvessels are extremely numerous and there may be dilated blood spaces. Frequently, perhaps in the great majority of cases, a definite connexion between the gland-containing cellular islets and the endometrium is to be found, the utricular glands and interglandular stroma dipping down into the myometrium, evidently continuous with the glandular constituents of the tumour. A microscopic section would of course show several of these endometrial inclusions as islets completely surrounded by muscle. This encroachment of endometrium on myometrium is not uncommon in hypertrophic endometritis and sections of the latter might show an occasional inclusion, but we do not think the presence of such merely directly under the endometrium in the absence of any definite tumour formation would justify the name of adenomyoma.

T'he cases here related will illustrate the foregoing sketch.

CASE 1.-We are very grateful to Mr. J. Bland-Sutton for this case. The patient was 49 years of age and had sought advice for severe hæmorrhages occurring over a period of three years. She was a multipara and her last pregnancy occurred six years previously. The diagnosis of fibromyoma of the uterus was made and consequently supravaginal hysterectomy was performed. The uterus was five inches in length and before section the appearance denoted the occurrence of an intramural fibroid. However, on section no capsule to the growth could be observed and the whole wall could be differentiated into three layers: 1. A layer of ragged endometrium. 2. A mass of striated tissue the fibres of which intersected each other in all directions. The absence of whorling was readily noticed. 3. A layer of ordinary uterine muscle about one-third of an inch in thickness. This condition existed in the whole uterine body. On microscopic examination the growth was found to be characteristic of adenomyoma. Gland spaces occurred throughout the sections; an abundant stroma resembling in every detail the tissue met with immediately under the lining epithelium of the uterus separated these tubules from the surrounding fibro-muscular structure. The epithelium of the tubules was columnar in shape and these were placed on a basement membrane which at every part was quite intact. No cilia could be detected in any of the spaces, but the epithelium otherwise resembled that of normal endometrium. At certain parts the endometrium could be seen dipping into the uterine wall so that here and there the rich lymphadenoid tissue around the acini communicated directly with that in the endometrium. At other parts the muscular fibres of the uterus could be seen encroaching on these peninsula-like ingrowths, and eventually on the muscular fibres becoming approximated an islet consisting of uterine endometrium lay inclosed in muscular tissue.

CASE 2.-For the kind permission to use this case we are indebted to Mr. F. B. Jessett. The patient was aged 33 years. She had been married 11 years. She had had two children and two miscarriages. Her previous health had been good and the menstrual history was unimportant. Three years previously when five months pregnant she fell from a train ; she was not hurt but was much frightened and consequently aborted. She was confined to bed for three months with pelvic pain and attacks of shivering. Ever since menstruation had been irregular, there had been three or four severe floodings, and she seldom went more than nine or ten days without some hæmorrhage. There were no bladder or rectal symptoms. She was not markedly anæmic. The uterus, which was removed by vaginal hysterectomy, was of about the size of a three months pregnancy. The cavity was three and a half inches long by one and a half inches broad towards the middle. The walls were thickened on all sides especially ventrally where the distance from serosa to mucosa was two inches. There was no encapsulation of this part. Three strata could be determined-a layer 'under the endometrium a quarter of an inch thick, a roughly reticulated stratum in the middle, and an external regular muscular layer half an inch thick. Two small polypi of the respective sizes of a tilbert and a pea were found projecting into the cavity near the funclus. (Fig. 3.) Microscopically the tumour consisted of muscular tissue, the 
strands running in all directions, and a relatively smaller proportion of well-formed gland tubules. There was practically no lymphadenoid stroma around the epithelium and,

FIG. 3.

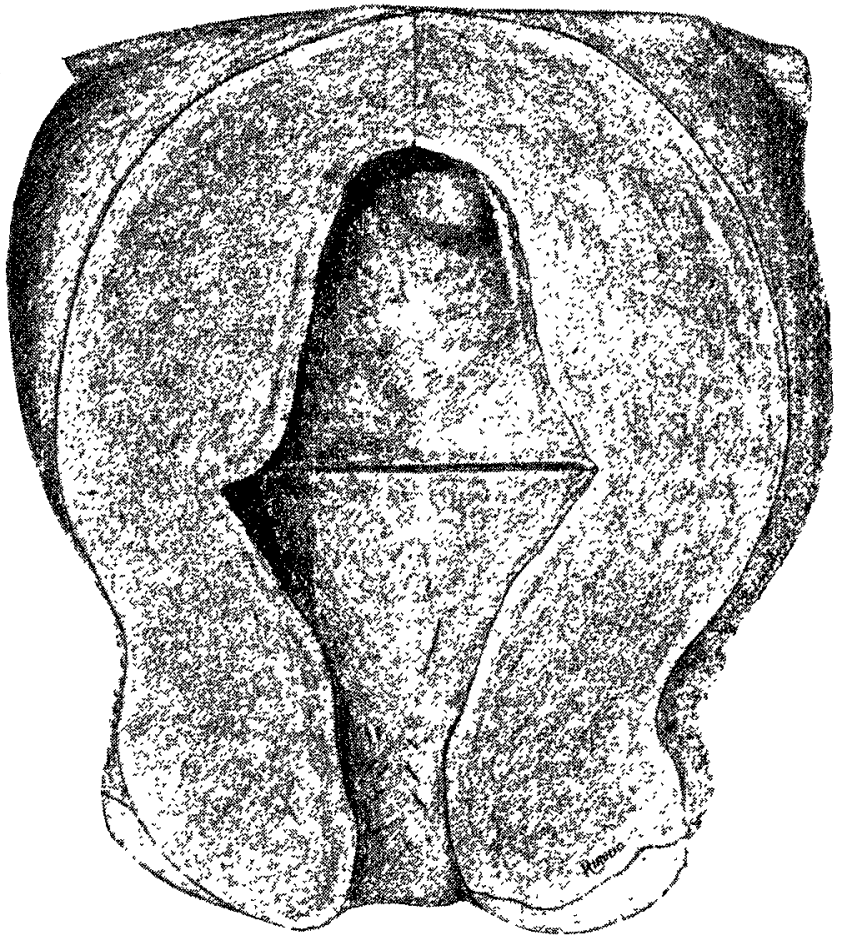

Adenoma uteri diffusum benignum. (Mr. F. B. Jessett's case.)

save for the intervention of a few connective tissue fibres at parts, it rested directly on the muscle. The epithelial cells were cylindrical and their nuclei lay close to the basement membrane. There was a tendency to intraglandular plication so that the contour towards the lumen was a wavy circular line. The fibrous tissue and muscular stroma followed these indentations. There was no round cell infiltration anywhere observable. The muscular stratum under the serosa was free from gland canals.

CASE 3.-For permission to make use of this specimen we are indebted to Professor Murdoch Cameron and Dr. Alexander McLennan. It was removed from the anterior lip of the cervix by Professor Murdoch Cameron who described the appearance of the tumour at the time of its removal as resembling very closely a multilocular cyst. The patient had all the symptoms which are found in association with intrauterine polypi. 'The tumour attained the dimensions of a cocoanut and on examination it was exceedingly like a multilocular ovarian cyst, the superficial parts of the tumour being raised into irregular masses by cystic cavities in the growth varying from the size of an orange to very minute glandular spaces. The covering of these cysts was very thin, while the portions intervening were of firm consistency. On section it was found to be composed for the most part of cavities which contained mucus and here and there free communication existed between neighbouring spaces. The fluid on boiling did not coagulate. These spaces were separated by tissue which to the naked eve seemed to be fibromyomatous and in a somewhat cedematous condition and on microscopic examination these portions were found to be in a degenerated condition, the stain being faintly taken up. The cystic spaces were found to be singularly beautiful in the perfection of their structure, resembling very closely the microseopic characters of an ovarian cystadenoma. The glandular spaces were lined by a perfectly uniform row of columnar epithelium which had an intact basement membrane resting directly on the surrounding fibro-muscular tissue. At the base of each cell there was a single nucleus which took up the stain readily. In many of the spaces well-marked papillomatous projections existed which extended in the more marked papillæ almost to the opposite wall of the cavity, a strand of fibro-muscular tissue following the epithelium into the lumen. Such was the degree of projection at certain portions that the apices of adjacent papillæ met and the epithelium at the point of contact disappeared, so that a space was thus formed in a secondary manner from these two papillæ. 'This space resembled the original glandular formations in every respect. The formation of such an adenomatous structure is exactly analogous to that which is found in the tubes in cortain cases of salpingitis. In other spaces the projections were extremely small, so that the lining epithelium had simply a number of small undulations next the lumen. In some of the larcer cavities where cystic distension harl been very great the epithelinm had com. pletely disappeared and here and there a fow flattened cells representerl what was once a well-detined cylindrical epithelium. Tn such spaces the fibro-muscular tissue formed for the greater part the limits of the cavity. $\Lambda$ corvical adenomyomatous polyp of such dimensions as the above: must be of very rare occurrence (Fig. 4).

FIG. 4.

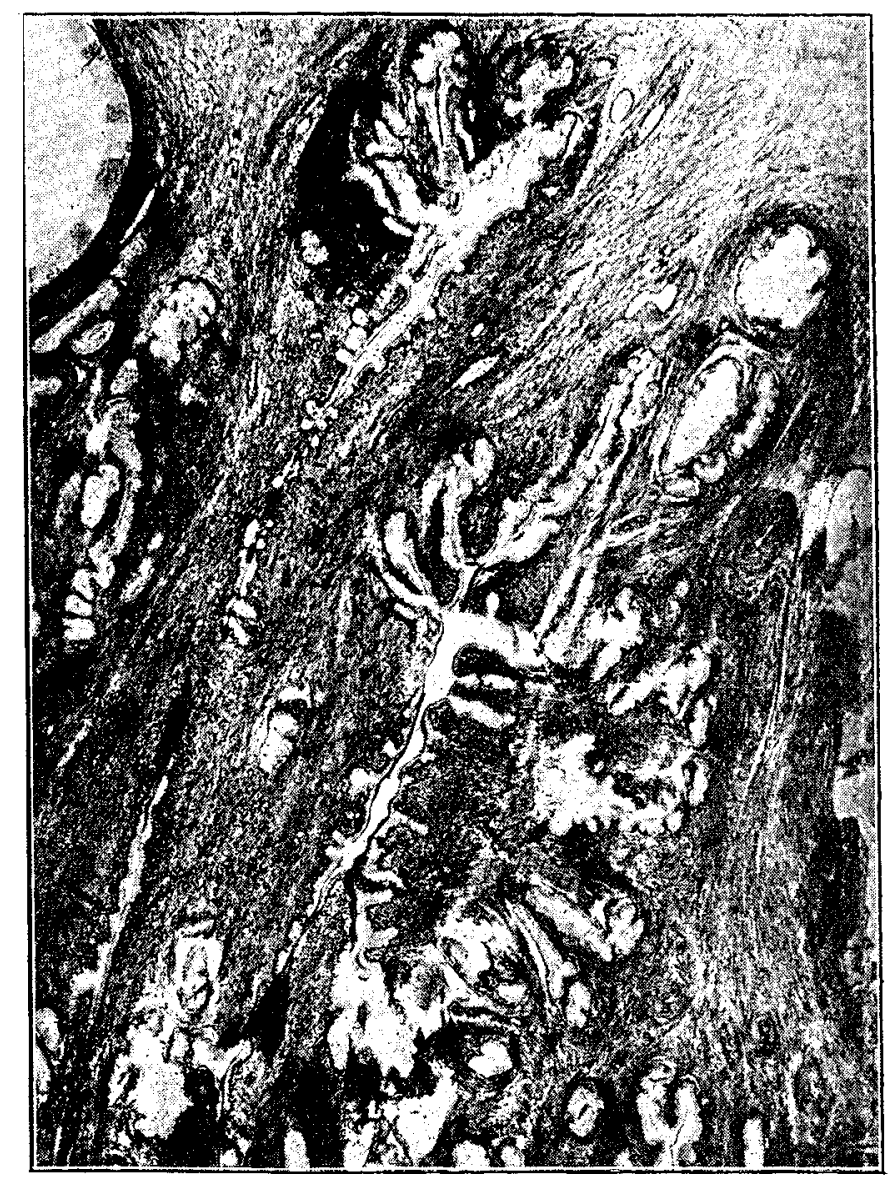

Section of a cervical atenomyomatous polypus showing subdivision of gland spaces.

CASE 4.--The patient was aged 39 rears, married, and the mother of four children. She had been delicate in childhood. Menstruation had started at 14 years of age. She had always been regular save for the intermissions of pregnancy but the periods had always been of long duration, nine days on the average and fairly copions. She was blonde and pale. Lately, the onset of the period had been accompanied by severe pain referred to the lower part of the abdomen and there had been severe hamorrhage at and between the periods. The uterus was not felt to be enlarged bimanually but painful under the examining hand on the fundus. The ovaries appeared to be normal and were not painful; the tubes were normal. Bimantally, with one finger in the rectum, the fundus nteri towards the left was excessively tender. There was no blackler trouble. The patient was of a constipated habit and required to keep the bowels loose by medicine to obriate pain on refecation. Laparotomy was performed and the uterus was removed. The uterus was normal in size but on the fundal angle just behind the uterine junction of the left tube there was a slightly raised flat whitish circular patch under the intact peritoneum. In cutting into it it was hard to the knife, almost regularly hemispherical, and approached the cavity on its inner convexity. It was of about the size of a half walnut. It was circumscribed by normal uterine tissue. It appeared to be a fibromyoma and its true nature was only discovered after microscopic section ; consequently we were not so careful as we might have been in the rough section and though serial sections were afterwards made in no case unfortunately was one obtained without muscular stranrls intervening between the endometrimm and the tumour proper. Microscopically the tumour was composed of bundles of muscular tissue running 
in various directions, inclosing and separating from each other, many well-formed circular, oval, or irregularly shaped gland acini. In the smaller tubules the epithelium was columnar, in the larger cubical, and each cell was occupied by a round or oval nucleus. The epithelium, too, at various parts of the tumour was ciliated (Fig. 1). At some parts there was a fair amount of lymphadenoid stroma between the acini and the muscle, at others the epithelium abutted directly on the muscle. Seldom were two sections of gland tubules found in the same islet. 'The blood-vessels were fairly numerous and had hypertrophied walls. Gland cells existed quite close to the serous coat. The endometrium was apparently normal.

Several theories of origin have been put forward. The inevitable microbic origin has received the support of some French observers mainly on the slender ground of occasional leucocytosis. Cullen has described the presence of giant cells but no tubercle bacilli have been found. Eschoff considers that the peritoneum covering a myoma may dip into it, be cut off, and by proliferation form the adenomatous constituent. This view presupposes the probability of metaplasia of endothelium into epithelium. It has received no independent support. Most continental and American observers refer the tumour to mucosal origin. Von Recklinghausen ${ }^{5}$ was strongly of opinion that uterine adenomyomata almost exclusively owed their origin to persistent remains of the Wolffian duct and of his 33 cases referred only one to a mucosal origin. In early fœetal life the Müllerian and mesonephric ducts lie in close proximity from the kidney to the urogenital sinus. Below, the Müllerian ducts coalesce to form the uterus and vagina; above, diveroing, they form the Fallopian tubes; and it is at the uterine junction of the latter with the uterus that the Wolffian ducts lying dorsally come to have an intimate relation with the uterus. Persisting as rudimentary canals in ruminants and swineGartner's canal-the Wolffian duct in the human adult has as a rule entirely disappeared except the terminal portion inclosed in the substance of the neck of the uterus and still distinguishable but only by means of cross sections as an extremely narrow tubule (Beigel, H. Dohrn). Rest cells derived from the Wolffian ducts have been found under the serosa, especially near the tubal angles, by Klein and others. Adenomyomata have been found over the course of the Wolffian ducts-in the Fallopian tubes, broad ligaments, and vagina. The glandular elements arising from the Wolffian remains in the uterus would stimulate a hyperplasia of the muscle and thus form the other element of the tumour. This explanation of von Recklinghausen would seem to account for subserous adenomyomata towards the uterine cornua posteriorly but it breaks down with regard to submucous adenomyomata, dorsal or ventral, or more or less generalised growths. The evident connexion between the endometrium and the glandular islets of the tumour and the identity of their component parts seen in so many cases make the mucosal origin of these practically certain, and even though no endometrial connexion is evident it is improbable that adenomyomata practically identical histologically could have two such very dissimilar modes of origin. Besides it is unlikely that perfectly formed tubules of such a highly specialised structure as ciliated epithelium could originate from embryonic remains, which have presumably long lain dormant, and the fact that cilia are present in a tumour which has intact peritoneum over it seems to point strongly to a connexion with the uterine cavity. 'The failure to establish an endometrial connexion in a microscopic preparation may be due to the fortune of the particular section and the connexion might be revealed by serial sections, but if even then it is not obtained a mucosal origin is not negatived, for by the growth of the muscular constituent the tumour might be insulated. The presence or absence of a lymphadenoid setting of the acini does not point either way, for in Case 4, where no endometrial connexion was determined by the sections, there was at parts more or less lymphadenoid stroma, and in Case 3-a polypoid growth-and in Case 2, where there was presumptive evidence of endometrial origin, there was practically none.

The association of adenocarcinoma with adenomyoma may be more than accidental. Beyea ${ }^{6}$ considers that carcinoma of the uterine body may arise from adenomyoma. We are

5 Die Adenomyome und Cystadenome der Uterus und Tubenwandung, 1896. deeply indebted to Dr. Louise McIlroy of Glasgow for providing us with a section showing at one part typical adenocarcinoma with small round-cell infiltration, intraglandular inverting and extraglandular everting of closely packed dis-

\section{FIG. 5.}

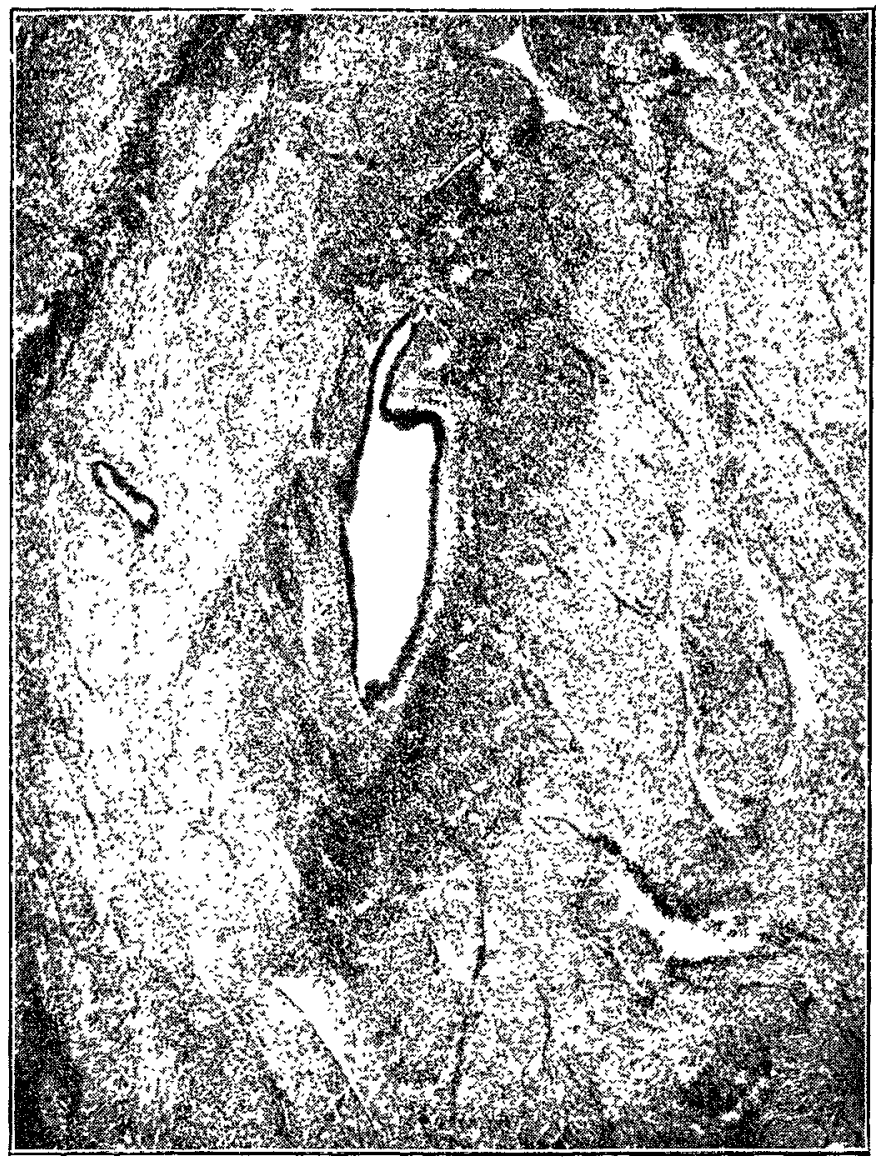

Section of a tumour showing typical adenomyomatous formation.

FIG. 6.

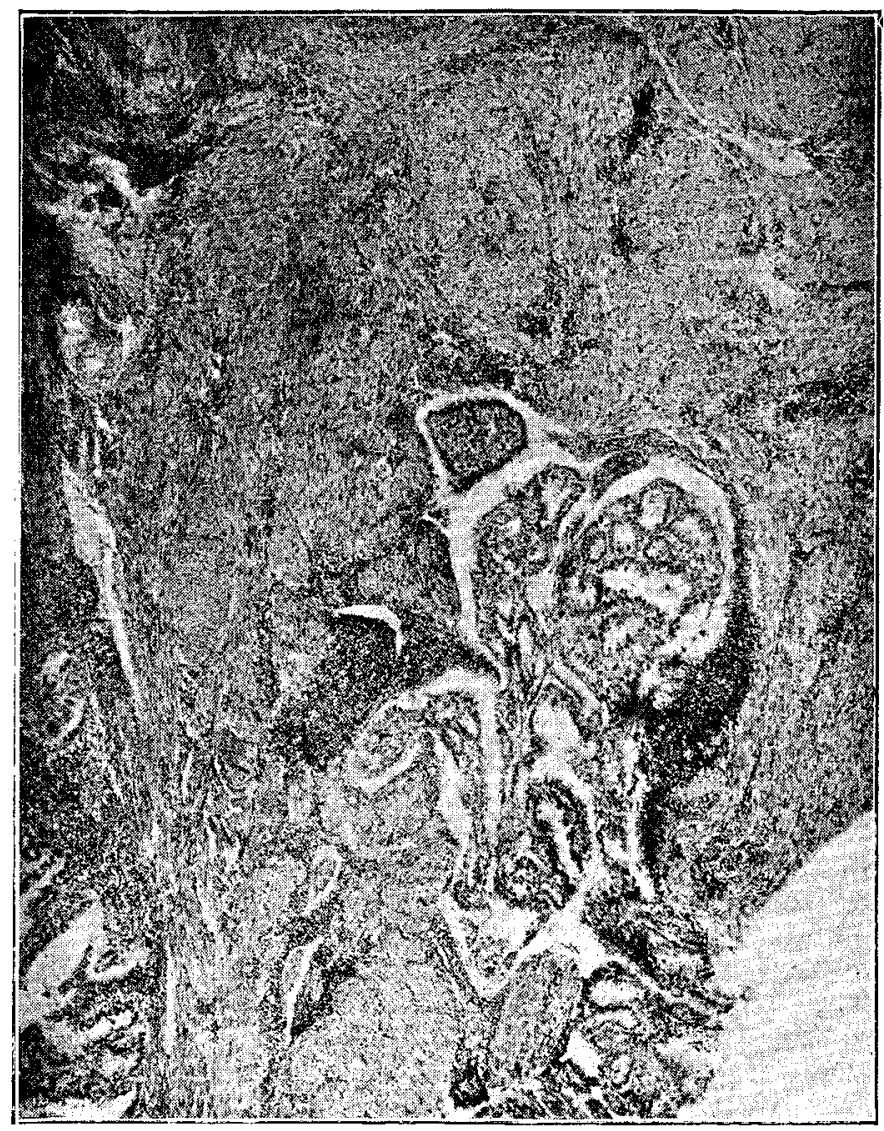

A different part of the same section showing adenocarcinoma.

torted epithelial cells several layers thick and poor in nuclear staining, their basement mombrane lost, and the interglandular stroma rerluced to a minimum, and at another part 
perfectly formed gland tubules composed of a single row of columnar epithelial cells and the nuclei well stained, the basement membrane intact, the surrounding stroma of lymphadenoid tissue and the enveloping muscle-typical adenomyoma. Figs. 5 and 6 are reproduced from microphotographs from different parts of the same section. Fig. 6 seems to show the transition from adenomyoma to adenocarcinoma through the intermediary stage of malignant adenoma, the gland canals at that part being lined with a single row of cylindrical epithelium. We have searched several hospital and private collections of uterine tumours without coming across this condition.

To sum up, we would suggest the following as the stages of these tumour formations : first, an ingrowth of the structures of the endometrium into the muscular wall, as is seen in hypertrophic endometritis - the stage of "glandular inclusion".; second, a hyperplasia of the inclusions and a progressive infiltration stimulating a hyperplasia of the muscle-the stage of "adenomyoma benignum"; third, a loss of relations between glandular and muscular elements, the growth of the former outstripping that of the latter, inversion and eversion of the epithelium with a consequent displacement of the interglandular stroma and an encroachment on the muscle, the irritation of the growth causing the round-cell infiltration-the stage of "malignant adenoma"; and fourth, the stage of adenocarcinoma, the loss of relations between one epithelial cell and another, the riotous proliferation and heaping up of immature epithelial cells breaking through the restraining basement membrane, invading and destroying the adjacent muscle.

We have received much help from various friends in the way of specimens of uterine tumours and microscopic slides. We beg to thank Dr. Harold R. D. Spitta of St. George's Hospital for the excellent microphotographs which he has taken for us.

\section{g attirtor} OF

\section{HOSPITAL PRACTICE, BRITISH AND FOREIGN.}

Núlla autem est alia pro certo noscendi via, nisi quamplurimas et morborum et dissectionum historias, tum aliorum tum proprias collectas habere, et inter se comparare-MoRGAGII De Sed. et Caus. Morb., lib. iv., Procemium.

\section{SIR JAMSETJEE JEEJHEBHOY HOSPITAL, BOMBAY.}

A. CASE OF OCULAR DEFECTS ASSOCIATED WITH CONGENITAL DEFORMITY OF THE CRANIUM (OXYCEPHALY)

(Under the care of Captain E. F. Gordon 'TUCKER, I.M.S.)

THE patient was admitted into the wards of Captain Tucker in the Sir Jamsetjee Jeejhebhoy Hospital early in September, 1903, for an attack of malarial fever which rapidly responded to treatment. The curious condition of the eyes was at once observed and examination of the cranium showed that the occipital region was very deficient and that the posterior part of the skull was almost on the same plane as the back of the neck. After his head had been shaved the "steeple-shaped" character of the cranial vault was evident.. He was a Mahratta and stated that his age was about 20 years and that his eyes had always been prominent. His father was alive and in good health and had no peculiarity of the eyes or the face. His mother died about five years previously, apparently from phthisis ; there were three sisters who died young and there was one brother living who had not ocular defect or peculiarity. The patient's work was to look after cattle. He answered questions intelligently; he gave no history of headaches and had always had good health. Vision for distant objects was good. He was of normal height, build, and development. The cranium showed a projection in the form of a ridge from the centre of the vertical portion of the frontal bone to the central point of the vault, which was situated one and a half inches in front of a line drawn perpendicularly upwards from the external auditory meatus. The marked bulging in the temporal regions present in the case of congenital proptosis associated with a curious formation of the cranium in a boy, aged seven years, who showed evidence of some mental deficiency, described by $\mathrm{Mr}$. H. Work Dodd and $\mathrm{Mr}$. W. H. McMullen in The LANCET of June 13th, 1903, p. 1665, was not evident in this case. The shape of the face was natural. The nose was well formed. The palate was very high and arched and met at the uppermost part in a deep sulcus. The teeth were very good and not at all crowded together. The neck was of normal shape and there was no enlargement of the thyroid gland. Coördination of muscular movement was quite natural. The measurements of the head and face were as follows: horizontal circumference. $49 \frac{2}{2}$ centimetres; naso-occipital arch, 34 centimetres; binauricular arch, 34 centimetres; height of the orbits, $4 \frac{1}{2}$ centimetres; breadth of the orbits, 5 centimetres; transverse diameter (measured with callipers), $12 \cdot 2$ centimetres; anteroposterior diameter, $16 \cdot 2$ centimetres ; suboccipito-frontal, 16.2 centimetres; distance between the two external angular processes, 11.4 centimetres; and height of the frontal bone, $11 \cdot 8$ centimetres. The cephalic index was therefore $75 \cdot 3$. Certain ridges on the cranium were well marked; the superior temporal line stood out along the whole side of the skull; the superior eurved line of the occipital bone could be felt and the external occipital protuberance was of the size and shape of a marble. There were no definite parietal eminences. The intermal condyle of each humerus was very prominent and this enlargement was symmetrical; the internal condyle of each femur was also large and there was the slightest possible amount of genu valgum. The proptosis could be well seen in the photographs (see illustrations). Quite two-thirds of the globe were in

FIG. 1.

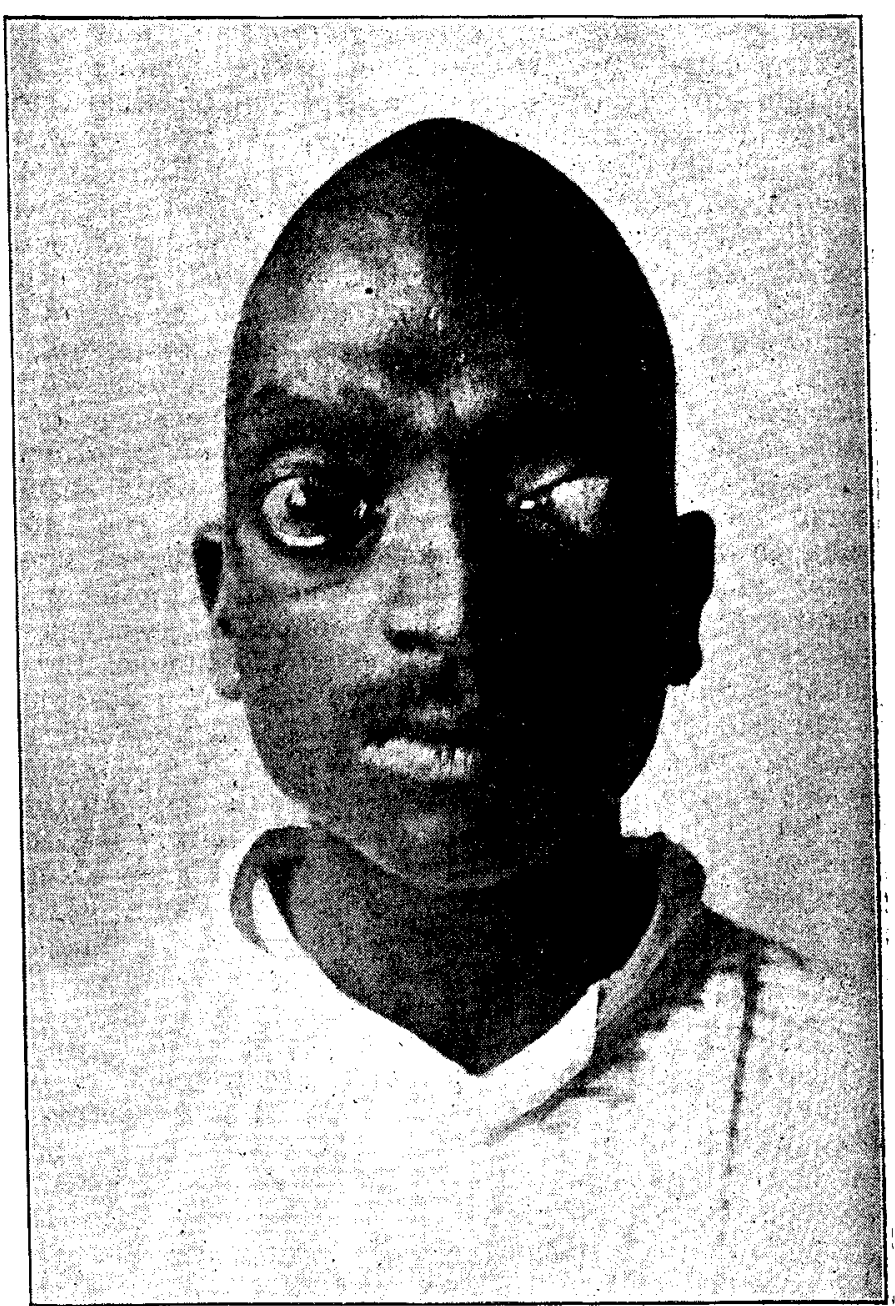

Aspect of patient, front view.

front of the orbital margin ; a little pressure on each lid caused still more proptosis and pain ; there was more proptosis in the right eve than the left and it could be moved laterally by the fingers but this was painful. Vision was good; there was no ny'stagnus. Hearing was good. There was external strabismus on both sides but the left eye was the most affected. 'The movement of the right eje, when acting alone, was impaired in the inward dircetion and slightly so in the npward direction. Similarly there was impaired movement with the left eye acing alone but the movements 